\title{
Study on Innovative Interactive Teaching Mode in China
}

\author{
Ping Guo \\ School of Economy and Management, Shijiazhuang \\ Tiedao University \\ Shijiazhuang, China \\ guo_gp@sina.com
}

\author{
Hongkai Guo \\ Department of Mathematics and Physics, Shijiazhuang \\ Tiedao University \\ Shijiazhuang, China \\ hkguo@yahoo.com
}

\begin{abstract}
Interactive teaching is the important indication of the reform of the contemporary education democratization in teaching methods, and it emphasizes the active participation of students in the process of teaching and respecting the principal position of students. It strives to achieve the interaction between teacher and students, between student and student during teaching, so as to realize the education target of cultivating innovative talents. The paper firstly has a brief review over the study on interactive teaching methods at home and abroad. On this basis, it study the three models of interactive teaching in the current in China, such as The dual two-way teaching mode, the link teaching mode and three module teaching mode. With interactive teaching practice, it proposes the implementation of interactive teaching methods, like "Case interaction" teaching method, "Multimedia" teaching method, "Second classroom" teaching method, etc.
\end{abstract}

Keywords-interaction;teaching;mode;expansion; multimedia

\section{INTRODUCTION}

Along with the changing of the social demanding for talent quality in the future, Innovation ability becomes a very important aspect to determine the standards of talents. To cultivate student's habits of innovation, we must respect the student individuality, admitted the diversification of student in their interest and personality. This requires that we should create conditions for students to discover problems, analyze problems, solve problems, summarize rules, form inquiry learning mode, and put forward a new theory and new methods in the teaching process. During the teaching process, only sufficient interaction between teachers and students or between the students, and give students fully discuss communication time, give students the opportunity to observe and practice with their hands, can we build an active exploration, continuous innovation atmosphere, which benefits the development of students' intellectual potential, the improvement of their comprehensive quality and the cultivation of their innovative ability.

\section{THE CONNOTATION OF INTERACTIVE TEACHING MODE}

The interactive teaching refers to a kind of teaching method, which through creating a multilateral interactive teaching environment, in the process of teaching from equal communication of both sides, achieving collision and blend of different point, then to stimulate the initiative and exploratory from both sides in the teaching, and to improve the teaching effect. Based on the modern education psychology, the theory of education behavioral science and the teaching methodology, on the premise of changing the teaching idea of the faculty, through the use of a series of effective teaching methods, to achieve positive interaction between teachers and students, between the students parents and support staff, which causes the student to grasp the knowledge firmly what should be learned, and to foster and improve the comprehensive ability at the same time. Basing on this, the interactive teaching studied in this paper compared with the traditional narrow concept has been broadening. Due to the implementation of the interactive teaching as a systematic project, Therefore the research is not limited to how to realize the interaction between the classroom, but on the basis of considering the various factors affecting, combine the improvement of external environment and the goal of classroom teaching, discussing how to realize the objective of interactive teaching way from system design, from selection of teaching mode and from the use of teaching method and other aspects in the current teaching atmosphere. $^{[1]}$

\section{DEVELOPMENT OF INTERACTIVE TEACHING MODE}

"Interactive teaching" was created in Harvard University in 1918, has been widely used as a kind of innovation of teaching method. Since 1970's, the "Interactive" teaching has achieved rapid expansion as a special field of study. "Interactive teaching" is a new type of teaching mode which guiding from the modern teaching ideas and the modern teaching theory, and fully embodies the training students' thinking as the core. The teaching model is followed the principle of "student is the main body, teacher is the leading", give priority to heuristic teaching, students were under the guidance of teachers, through the investigation and study, group discussion, share their experiences in design and other ways to learn. And teachers is in a dominant position in the whole teaching process, as a role of guiding, supplementing, inductive and perfecting, having equal dialogue with students, which forms two-way interactive relationship. ${ }^{[2]}$ 
Scholars of different subjects have developed a lot of achievements in the aspect of interactive type, one of the most representative is: (1) the British scholar B.J.Ashley divided the classroom interaction between teachers and students into three types such as: teacher center type, student center type, knowledge center type; (2)R. Lippitt and R.K.white divided the teacher leading behavior in class into three categories as: authoritative type, democratic type and laissez-faire type, and thus formed the teacher imperative, consultation between teachers and students and non-interference in each other between teachers and students. From the forms, the interactive teaching can be divided into: explicit interaction and implicit interaction. The explicit interaction can be seen from the warm atmosphere from the class, students are under the drive of the teacher. Such as play games happily, discuss, etc; " Implicit interaction" seems that the classroom atmosphere is not very warm, but students may be seriously ponder over a problem or organization of language... This is actually a kind of "move", but it is not easy to be perceived. Teachers should not believe that only cheerful class is a good lesson. A good teacher will give students the time thinking and grasping, and this can let students learn knowledge, and leave meaningful things in the students mind after class.

In the early 1980's, the interactive teaching was introduced in China, and has been gotten more and more attention. After 1995, the research result is increasing. In China, the original study of the "Interactive" teaching is from the primary school, and this is directly related to the characteristics of primary school education. After 2000, "interactive" teaching has been get widely attention by colleges and universities, the original in English class teaching and other language teaching, now was developed to various disciplines, such as math, science, philosophy, medicine, economy and also other professional subjects were involved. Nowadays the breadth and depth of the current research on the "interactive" teaching pattern has been kept pushing on, the "interactive" teaching mode has been carried on a beneficial extension study. The basic form and the core idea of "interactive" mode are to stimulate students "interest" in learning through interaction. Simulating reality as much as possible, the students can be more close to the reality, in order to master the ability to cope with the complex environments and means. "Interactive" teaching mode has been widely extended to vocational training, radio and television, medical technology, management, tourism and other industries teaching field.

\section{THE TYPES OF INTERACTIVE TEACHING MODE}

Throughout the research achievements of previous scholars, the more standard and more feasibility of interactive teaching mode specification mainly includes:

\section{A. The Dual Two-way Yeaching Mode}

Teaching mode should convert from the traditional "one element unidirectional plane" teaching mode to modern "binary two-way type" three-dimensional teaching mode. By turning the mode of "teachers' active teaching, students' passive acceptance" into the interaction between teacher and student, student and student, ${ }^{[3]}$ which is specific as shown in figure 1:

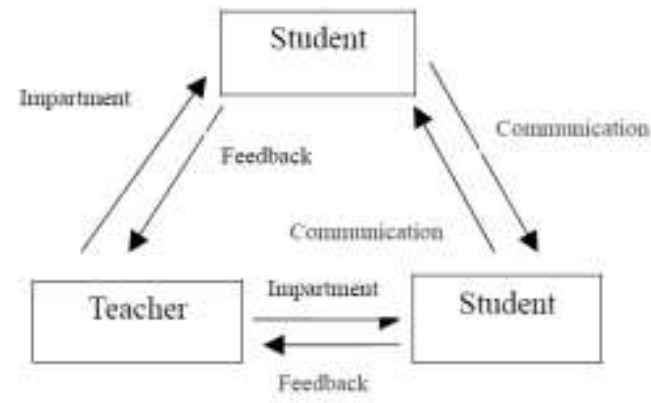

Figure 1. The "dual two-way type" interactive teaching mode

From the above figure of "dual two-way type" interactive teaching mode, it can be seen easily that the interactive communication and feedback exists not only between teachers and students, but also between students and students. Teachers will pass knowledge to students, and students can communicate with the teacher through feedback. ${ }^{[4]}$ Not only between teachers and students, but also between students and students exists the transmission of information and communication, and causing further exchanges and communication with the teachers. Although this mode has not divided the whole teaching link into several stages artificially by appearance, while it made interpretation of the interactive teaching mode from the communication and feedback closed loop process, but the starting point of thoughts also can't be separated from the idea that teachers as the leading factor, take the student as the main body, fully arouse the enthusiasm of students and participation awareness, through discussion and communication to achieve the improvement of problem solving ability by imparting knowledge.

\section{B. The Link Teaching Mode}

The link teaching mode includes both the teachers and students interaction, and the students and student's interaction. Interaction between teachers and students throughout the teaching activities, and students' interaction is mainly manifested in group activities and group of international communication. ${ }^{[5]}$ The specific pattern as shown in figure 2:

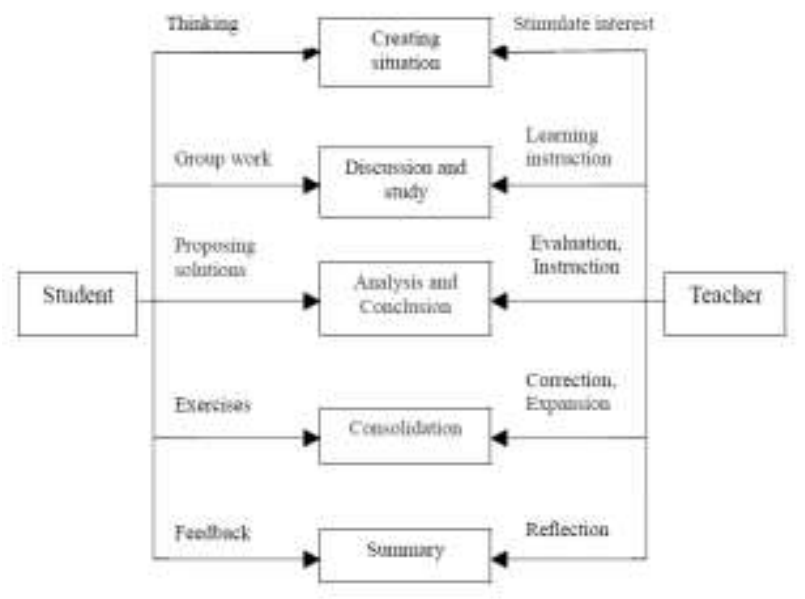

Figure 2. The link interactive teaching mode 
From fig. 2 we can see that, this model includes five links, such as the creating situation, discussion and study, analysis and conclusion, consolidation, and summary. creating situation aims to lead to problems that attract the attention of students, arouse their interest in learning, and thus causes the student to think of the problem. In the establishment of situation, the teacher should contact the life experience of student, employing the physical situation, story situation, problem situation, multimedia situation, talk situation, ask questions ably, and trigger students' interest in further thinking. In the phase of discussing the research, generally by the way of grouping method, through observation, investigation, communication, discussion, practical operations such as division of labor and collaboration, students can link previous problem situation to carry on the discussion of research, finally puts forward the solution, the teachers in this section is to play a major role in learning, guiding and grasping the direction discuss and exchange of the students. In the analysis and conclusion link, based on the grouping discussion, each group members put forward solutions to problems, and adopt the form of communication from different groups or the whole class discussion. In this process, the teacher needs to teach students the method of knowledge induction, and make appropriate complement, to complete the construction of knowledge and diagnostic tests. Through learning knowledge, students just have completed a leap of cognition, but the whole process has not been completed, which also should be further consolidated and deeply expanded. The teacher should guide students to use knowledge and to solve practical problems. Teachers can by showing expanding materials, providing new changes the problem of environment, so that the students can make further knowledge, improve the expansion and application ability. The final phase is summary, through students' self evaluation and teacher evaluation, to achieve the teaching goal of founding problem, solving problem, summarizing experience and lessons and improving ability, etc.

\section{Three Module Teaching Mode}

This mode is perception--exploration--feedback teaching method according to the law of students' activities. ${ }^{[6]}$ As shown in figure 3 :

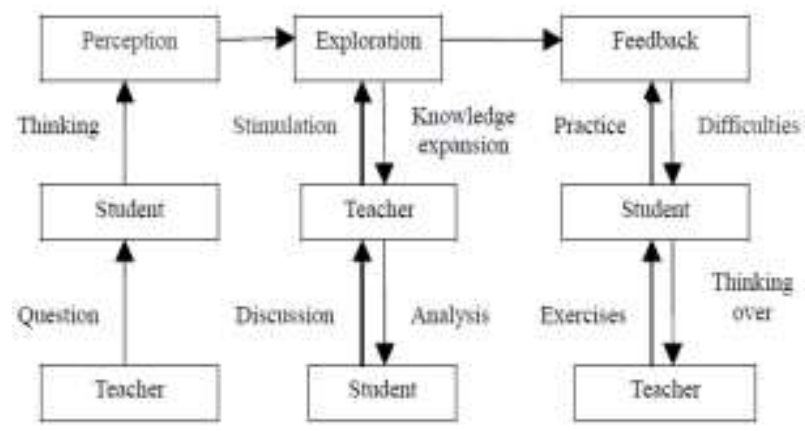

Figure 3. Three module teaching model diagram

Although the three-step teaching mode only was divided into three stages on the surface, but the basic idea has no too big difference from five links "interactive" teaching mode. Which are both first establishing situation and putting forward the problem, and then guiding the student to discuss and communicate with each other according to the proposed problems, and finally drawing the conclusion. And based on this, through expanding practice and strengthening knowledge consolidated, and summarizing experience and lessons, so as to guide the teaching and practice in the next step. Compared with five link model, the second module in three module teaching method contains two links of discussion and study, analysis and conclusion. The third module contains the other two links of expansion and summary.

\section{IMPLEMENTATION OF INTERACTIVE TEACHING}

Through the analysis above it can be seen that although different teaching modes from different angle or different courses, but the basic ideas and views have consistency. Therefore, interactive teaching pattern in classroom teaching should follow the principle of the double main body, give full play to the initiative of teachers and students, to realize knowledge imparting and quality improvement through mutual communication and the exchange from each other. But considering the characteristics of subjects, on the basis of the implementation of classroom teaching, the extracurricular practice should be joined in. Specific to each different course, different teaching methods should be chosen. About the interactive teaching method, with the author's practice in teaching, the following implementation methods are explored and carried out.

\section{A. "Case Interaction" Teaching Method}

Creating situation, guiding the students to discuss and exchange, so as to realize the unification between the participation of students and guidance of teachers, to complete the improvement of imparting knowledge and creative ability on the basis of mutual communication. This method contains two parts of "Actuation" and "Interaction", the spirit throughout the entire interaction is initiative. "Actuation " is a prelude, and also set the keynote for the main body of the interactive teaching process at the same time. "Interaction" is the main carrier to achieve teaching goals. "Actuation" is through the whole teaching activity. The main strategy for actuating is to set the scene, the interaction can be built discussions around the "question list", and this kind of interaction requires teachers to design good questions with strict logical relation between front and back, processing layers by layers, and also dividing a problem into several small problems, discussing respectively, so as to achieve the overall understanding of the problem. "Case interaction" teaching method focus on extending the creativity and practical ability of students. Under the guidance of teachers, through the selection of cases, teachers should guide students to participate in some part of the whole teaching process, let students have the opportunity to show their personal achievements, so as to establish smooth communication between teachers and students and to establish information feedback channel, to promote together and improve the effect of education. ${ }^{[7]}$

Teachers should try to enjoy all students to participate in the activities, to form interactive atmosphere, by designing imitation forms, games, contests, and other activities. Specific ways: (1) Completion by the students independently. If the teaching contents are relatively easy 
to understand, the students can be asked to use the time in class or after class to prepare, to be "little teacher" by the students, at the same time, the students below the platform can experience the advantages and disadvantages of these "little teacher" lecture. Doing this can make the teacher understand the habit of the students to analyze problem, find out the degree of understanding of the teaching content, and also give students opportunity to exercise and can also understand the teachers' working hard, to achieve the double training goal of both ability education and moral education, thus teaching and learning could improve together. (2) The discussion method. This method refers to the students deep understanding of knowledge and enhancing their ability under the guidance of teachers, through the form of group discussion. Seminar is helpful for the students to cultivate the courage and ability of expressing their views, and the students inspire each other in class and inspire their potential thought spark, which make the classroom atmosphere actively, and fully arouse the students' enthusiasm in learning. Seminar also provides students opportunities to evaluate, treat their own point of view and the opinions of others correctly, and also be beneficial for the students to cultivate good human relations through communication, interaction. Because of the seminar is one platform of the students to show their individual specialty, so it can facilitate teachers to find the talent, and teach them according to their aptitude. (3) The game method. this kind of teaching method is to join the game elements in teaching activities, causes the student to place oneself in a pleasant, tense, confrontational, serious, incentive game atmosphere, promote students' individual ability for survival and team cooperation.

\section{B. "Multimedia" Teaching Method}

"Multimedia" teaching method is refers to the teacher use modern technology tools such as computer, multimedia, all kinds of software, to make teaching courseware for teaching. It has the advantages of vivid teaching, more intuitive education content and huge amount of information, etc; in addition, with the development of the network, the teacher can also download some audio or video courseware from the internet, use teaching resources more effectively. Multimedia teaching courseware is produced by a variety of media representation and hypertext structure, according to the requirements of the syllabus and teaching needs, through strict teaching design. It can describe various teaching problem vividly, active classroom atmosphere, improve the students' interest in learning, and broaden the students' knowledge. ${ }^{[8]}$

Interactive network teaching is an extension of the interactive classroom teaching under the internet environment, and is a product of the combination of interaction teaching and network teaching. Based on advanced network and multimedia technology, to exchange information transmission, realize the real-time interaction in the process of teaching and learning. Interactive network teaching made teaching interaction have flexibility, interactivity, advancement and openness, blend the real cases in the network into the real interactive teaching in the classroom. From finding information's and collecting data via the network, can make the students understand how to obtain all kinds of information on the relevant professional knowledge, promote the interaction between the teacher and student, student and network information interaction, find and solve problems, maximize students' subjectivity, get the best teaching effect. "Multimedia" teaching and interactive online communication method with the aid of the multimedia and network make the teaching process to be threedimensional. ${ }^{[9]}$

\section{C. "The Second Classroom" Teaching Method}

Classroom teaching is the first, but if only stay in the link of classroom teaching activities, the whole course of teaching is not finished. Teachers should also guiding students' learning, check the proficiency of grasping the knowledge and skills in extra-curricular activities, and let the students to observe in knowledge, scientific and interesting activities, to hunt and to understand the mystery of the in-class teaching content which did not understand, then to gain more comprehensive knowledge and master more practical skills. ${ }^{[10-11]}$

"The second classroom" teaching method will extend the classroom teaching to the real life, and through the effective use of multimedia and Internet, improve the teaching efficiency and teaching level unceasingly.

\section{ACKNOWLEDGMENT}

The paper is the section of the research results for the project "The Independent innovation research on promoting development through evaluation for economy and management colleges under teaching assessment of domestic universities", which is funded by Department of Educational Science Planning Project in Hebei Province in 2014.

\section{REFERENCES}

[1] Yun Chen, "Information Effect in Interactive Teaching," Proc. Advances in Computer Science, Environment, Ecoinformatics, and Education - International Conference(CSEE 2011), Springer Verlag, 2011, v 218 CCIS, n PART 5, pp. 496-500, doi: 10.1007/978-3-642-23357-9_88.

[2] Xiaomei Kang, "A Comparative Study on Theory of TeacherStudent Teaching Interaction Behavior Method,'Comparative Education, Apr. 2001, pp.42-46.

[3] Hua Li and Yunyong Wu, "Interactive Teaching Model Analysis," Journal of Shenyang Normal University, Social Science, Mar. 2008, pp. 77-79..

[4] Shen Bo, "Research on Double Main Body Interactive Teaching Based on Web 2.0 with Scientific Teaching Materials", Proc. Advances in Computer Science, Environment, Ecoinformatics, and Education - International Conference(CSEE 2011), Communications in Computer and Information Science, Springer Verlag, 2011,v 218 CCIS, n PART 5, pp. 423-428. doi: 10.1007/978-3-642-23357-9_75.

[5] Qingbo Meng and Chen Wu, "Interactive Teaching Mode of Model Construction," Journal of Tianjin institute of finance and trade management cadre. Jan. 2010, pp. 49-51.

[6] Shuyun Wang, "Interactive Classroom Teaching Model Construction and Evaluation," High school biology teaching, Oct. 2009, pp. 6-9

[7] Wang Yafang, "English Interactive Teaching Model Which Based upon Internet of Things," Proc. International Conference on Computer Application and System Modeling (ICCASM 20102010), IEEE Computer Society, 2010, v 13, pp. V13587-V13590, doi: 10.1109/ICCASM.2010.5622914.

[8] Bai, KeJia, "Research on Multidimensional Interactive Teaching and Application in Database System Concepts Course," proc. Advanced Materials and Information Technology Processing (AMITP 2011), Advanced Materials Research, v 271-273, Trans 
Tech Publications, pp. 1253-1256, 2011, doi: 10.4028/www.scientific.net/AMR.271-273.1253;

[9] Sun Dongling, "A Progressive Study of Interactive Teaching Pattern of College English in E-era," Proc. The International Conference on e-Education Entertainment and e-Management (ICEEE 2011), IEEE Computer Society, 2011, pp. 246-248, doi: 10.1109/ICeEEM.2011.6137797.

[10] Ding Diankuan, "The Application Study of MCU in Visual Classroom Interactive Teaching Based on Virtual Experiment Platform,"Proc. Advanced Research on Electronic Commerce,
Web Application, and Communication - International Conference(ECWAC 2011), Springer Verlag, 2011, v 143 CCIS, n PART 1, pp. 199-204, doi: 10.1007/978-3-642-20367-1_31;

[11] Xiu-Miao Zhou, "Reflection and Exploration of Interactive Teaching in College English Intensive Reading Classroom of Newly Built Universities Under Network Environment in Minority Areas," Proc. 2011 International Conference on Future Computer Science and Education(ICFCSE 2011), IEEE Computer Society, 2011, pp. 513-517, doi: 10.1109/ICFCSE.2011.131. 